\title{
Exchanges
}

In the Exchanges, we present conversations with scholars and practitioners of community engagement, responses to previously published material, and other reflections on various aspects of community-engaged scholarship meant to provoke further dialogue and discussion. We invite our readers to offer in this section their own thoughts and ideas on the meanings and understandings of engaged scholarship, as practiced in local or faraway communities, diverse cultural settings, and various disciplinary contexts. We especially welcome community-based scholars' views and opinions on their collaboration with university-based partners in particular and on engaged scholarship in general.

In this section, co-editor of this issue David Peacock interviews Stephen Huddart (President and CEO) and Chad Lubelsky (Program Director) of the McConnell Foundation, a historic supporter of postsecondary education across Canada. McConnell's investments in community service-learning, social entrepreneurial and innovation activities and social infrastructure programs and dialogues have made them a significant partner for many Canadian higher education institutions. Yet not all community-campus engagement scholars and practitioners, and Engaged Scholar readers, may have heard McConnell articulate for itself its aims and goals for Canadian higher education and society. This interview canvasses the scope of McConnell's work and interests in community-campus engagement, and sheds light on the actions of an influential private actor in the postsecondary sector.

\section{Funding Social Innovation in Canada: A Conversation with Stephen Huddart and Chad Lubelsky of the McConnell Foundation}

David Peacock: So what is the McConnell Foundation? What kind of foundation is it?

Stephen Huddart: The McConnell Foundation is the second oldest private foundation in Canada. We were established in 1937, and have a long history of supporting the postsecondary sector in Canada, beginning with a long relationship with McGill University. In the mid-90s, the Foundation began to professionalize. It has evolved since then to focus on both national initiatives and increasingly multi-sector partnerships designed to accelerate systemic change in Canadian society.

Our work is focused on Canada, working with the postsecondary sector, governments, 
charitable organizations of varying kinds, other foundations, and the private sector. We integrate our grant making activities with our investments, which has become an important part of our work. We've just concluded a decade of support for something called Social Innovation Generation, which sought to introduce the tools, mindsets, and approaches that social innovation, social finance, and social enterprise offer to solving complex problems. We've placed considerable emphasis on engaging the postsecondary sector in this work as well.

David: What goals or impacts are you seeking to produce through those investments?

Stephen: The foundation's mission statement is to engage Canadians in building a society that is inclusive, sustainable, resilient, and innovative. We are, in light of that, working to increase the adaptive capacity of Canadian institutions in the face of overarching challenges, like the need to transition to a low carbon economy, to support inclusive growth, to create opportunities for this and coming generations to be meaningfully employed and engaged in building a society that we all want. Working on economic reconciliation with Indigenous peoples is an important part of this.

We see the postsecondary sector as our natural partner, where we have deep relationships in many cases spanning decades, and where we continue to be engaged in enabling institutions to expand their 'civic footprints', to enable us all to be well-equipped to contend with current challenges and opportunities.

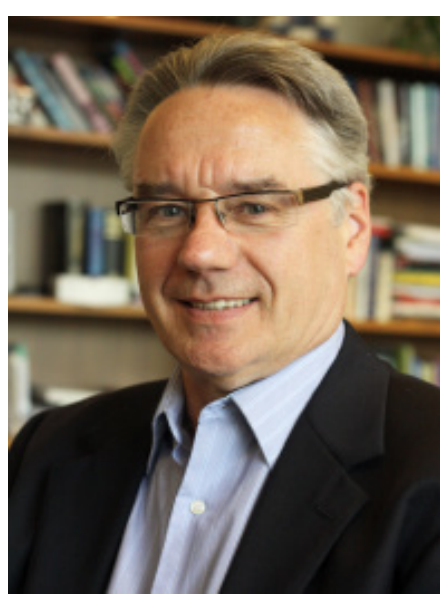

Stephen Huddart, President and CEO of the McConnell Foundation.

Chad Lubelsky: I would add that we would see the postsecondary sector as fundamental to equity in Canada, in terms of a key institution through which society helps to create a level playing field. Colleges, for example, are active in 3,000 communities, and universities of course are also situated in every region of the country. It's one of the key levers of progressive social change in our country.

David: Let's talk specifically about the relatively new social infrastructure project then with some of Canada's university presidents, and then also most recently, I understand, with Universities Canada (the peak advocacy body for Canada's universities). Could you talk about that project and what you hope to accomplish?

Chad: We view the social infrastructure project as an opportunity for postsecondary institutions to leverage all of the assets at their disposal for community well-being. In addition to the traditional research and teaching functions, the physical aspects at their disposal- 
the financial assets, hiring practices, and other components, which can be better used to support community well-being. With procurement, some colleges and universities work under laws where they have to always buy the cheapest possible option. Right?

\section{David: Often.}

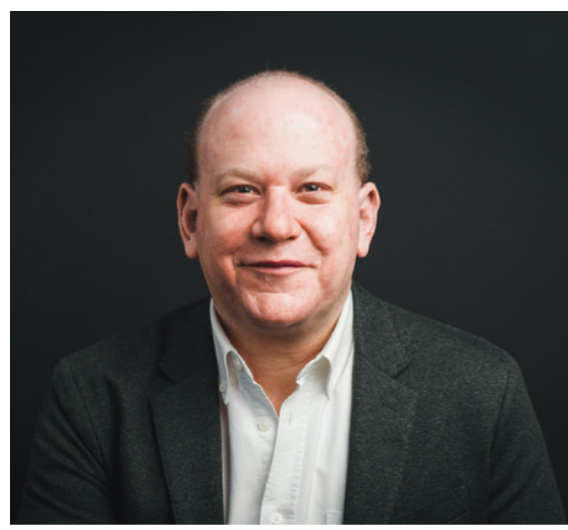

Chad Lubelsky, program director, McConnell Foundation.

Chad: So that might preclude buying local. As a postsecondary institution, if you buy local, you're increasing jobs and you're being a better community player? So it's one example of what we're talking about. What we're trying to do with this work is one, put into place shared resources and tools, so that institutions across the country don't always have to be reinventing the wheel as they take up this approach. Second, we're trying to enhance the narrative around the role of postsecondary education and its purposes, so that in addition to research and teaching, they become being more community-minded. And third, our social infrastructure agenda aims to support the individuals and the departments within institutions with the know-how to better do this kind of work.

David: So the postsecondary institution becomes further embedded in their local economies, the local culture; is that what you're saying?

Chad: Yes. And this would apply to finance, it would apply to research, it could apply to things like hiring practices and things like access programs. It really does run the gamut, and our expectation is that it's going to look different in different places.

David: In the 2000s, McConnell invested in community service-learning, and then as you have said, in the last decade, it invested in social innovation programming, funding targeting the research and teaching missions of universities. But this now is something a little different again. Perhaps it includes those, but it's now more than that?

Stephen: Yes, you could say that this is about expanding the institution's civic footprint. And so if we look at the needs of students today, coming into postsecondary education, that are facing some very complicated and complex challenges around career choice and a rapidly changing technology sphere, a number of overarching challenges to society, and so on, and so the university, by being more closely aligned with, present in, listening to, and engaging of community, I think provides a healthier, more robust, and productive place for formation, training, research, and so on, as Chad was saying, as a community- 
engaged partner. So, in addition to any work McConnell may have been doing, universities themselves have been engaged in community-based research for some time. The CFICE program at Carleton [Community First Impacts of Community Engagement] is a good example of an initiative designed to structure partnerships with community players in order to advance issues of priority community interest.

We're talking about the application of social innovation tools, social finance and social enterprise tools, and creating with our postsecondary institutions, robust, engaged, and productive partners for community in co-creating the futures that we all want. And we can't leave out the private sector here either. This is not just about civil society's goals. This is also about creating the companies; incubating the new corporations and the new social enterprises that will employ people in building an inclusive economy.

That's a pretty thick agenda, but it's one that I think is at a scale that is commensurate with the capacities of the institutions we're talking about, and the investments, frankly, that we make in them- to build more productive and prosperous futures.

David: And so Universities Canada_as the peak body and major partner-how would they assist you with that work in a different way than if you worked with individual institutions?

Chad: In a couple of ways. And I just want to go back to something that Stephen said. I would also bring it back to students by saying that our expectation is that the schools and students, in adopting all the tools that Stephen mentioned, have the opportunity to have an education that is more geared toward 21 th century. So that's part of the theory of change. For Universities Canada, what we've seen in other projects that we've done, when

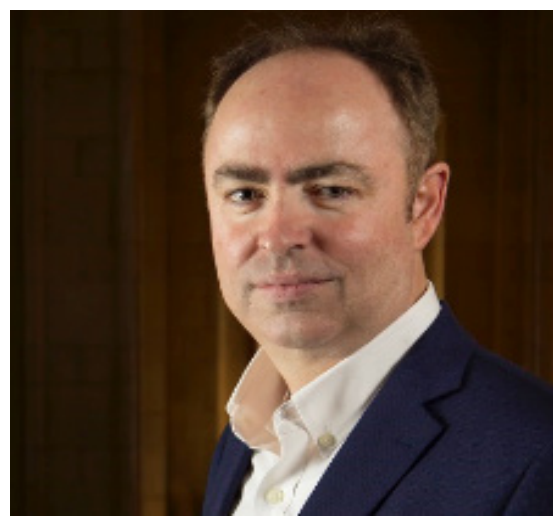

David Peacock, Executive Director, University of Alberta Faculty of Arts Community ServiceLearning we've issued a request for proposals, is that almost all of them did extremely effective work within the parameters of the grant. But what we saw less of was a network-wide effect. So for us, it was only logical to work with the associations - with Universities Canada, and with Colleges and Institutes Canada-on pan-Canadian initiatives, where those are the membership bodies.

We started off by seeing if there was interest among a group of presidents. Then they went to Universities Canada, who brought this opportunity to their members, who expressed interest in this kind of work. And there are specific things that a university president's office can do: Embedding ideas in the institutional plan, raising the profile, contributing institutional credibility. So with Universities Canada, the purpose is to socialize such approaches among presidents and others, and also to co-create pan-institution tools. This 
includes looking at common metrics. How do we measure this? How do we know whether we are doing this well? A platform and repositories so that the schools that are doing this kind of work have a place where other people are able to quickly and easily find and understand it. Potentially, we might have guides and toolkits. We're at a very early stage with the establishment of the partnership with Universities Canada, but those are things that we're thinking about, and we'd do in a sequenced approach, depending on what schools say back to us.

Stephen: We've been really gratified by the level of interest from the participating institutions, beginning with the roughly twenty presidents who came together in Vancouver in response to Andrew Petter's [President of Simon Fraser University] and my invitation. Nearly everyone that we invited came and spent half a day with us, followed by meetings with vice presidents and deans. There's an appetite for and openness to this kind of collaborative learning and re-engagement around new approaches to social innovation. It's really very exciting for us.

I also wanted just to mention a couple of the very specific ways that this is manifesting, just to make this a bit more real for your readers. One would be that we had an experiment that we ran last year called LabWise.

LabWise was tested with a number of academic institutions and community partners, including United Ways and others. This involved the co-hosting of a social lab over the course of a year that was focused on a complex issue and where social lab processes engaged students, faculty, and community partners in coming up with deeper, shared understanding of a complex issue, and developing prototypes or testable hypotheses for addressing it.

At the University of Victoria, for example, they worked together with stakeholders around the upcoming renegotiation of the Columbia River Treaty with the US, to bring into what was formerly a commercial treaty only, a new vision that is inclusive of Indigenous and environmental values, perspectives, and priorities.

Edmonton Shift Lab and the University of Alberta was one of the teams at the table, and their lab engaged in exploring the intersecting issues of race, poverty, and access to affordable housing. These processes exemplify a deeper type of engagement for an institution like a university or city hall. Vancouver is the home of another great example of this approach to engaged learning. There, City Studio engages seven postsecondary institutions - their students, their courses, and their professors in a long-term commitment to explore options for making Vancouver the world's greenest city.

These didn't originate with McConnell, but many of the schools with whom we are working operate social enterprise incubators-from the DMZ [Ryerson's Venture incubator], to Radius SFU [social innovation lab and venture incubator] on the West Coast, to the D3 [Concordia's District 3 Centre for Innovation and Entrepreneurship].

Chad: Almost every city will have one now. 
Stephen: We're seeing a real mushrooming of these spaces-in or within close proximity to academic institutions where students can have the institutional supports, and where community partners are often invited to co-create enterprise solutions to complex, interesting opportunities. They often involve technology, but not always. In the early stages of this work, we were struck by how rich a collaborative space emerges around an incubator. Now we're seeing a whole ecosystem emerging.

David: So I want to take a step back for a moment. Many have noticed the shifting roles of philanthropy and the roles that foundations play, where they no longer simply want to support charitable activity, but rather to actually achieve social impacts and social outcomes themselves, almost as policy actors in achieving those outcomes. So is that the way that McConnell would view itself vis-à-vis Canadian higher education, then? Do you advocate for certain positions that universities should hold or issues they should address? And is this example, this social infrastructure agenda, an example of how you're advocating for a particular vision of higher education?

Stephen: Well, it's a great question. I think I would say first of all that we can't advocate for anybody else changing the way they work if we're not prepared to do the same, and so as I think your question suggests, philanthropy itself is going through an evolutionary phase as we speak. It's not just McConnell by any means. Our partners in Canadian private foundations, partner foundations, community foundations, and indeed in foundations around the world are increasingly recognizing that we have first of all a responsibility to share what we're learning with others, to put our resources to work alongside those of other philanthropic players, and also public sector players-governments at varying levels of scale_-and private sector partners.

If we really want to move the issues that we're facing, we have to develop crosssectoral capacity and apply these new tools and mindsets to ourselves first and foremost. A good example of that would be the impact investing agenda. We're looking at our own endowments now and asking, "Well, how is it that we're just spending 3.5\% on granting and leaving the endowment unexamined and unapplied if our goal is to achieve social change? Why aren't we using that?" And indeed now we are, this is one of those questions that we would pose to the postsecondary sector, namely, how are you using your own resources to create the greatest possible impact at a time when it's critical that we do that?

David: So, you would call upon universities, then, to consider their pension funds, for instance, or other financial assets like endowments to invest in social impact bonds or something like that?

Stephen: Well, social impact bonds are just one of a plethora of instruments available. The field of ethical investing is maturing quickly and we believe that it's possible to responsibly invest endowment assets in products, companies, and programs that do not entail the 
acquisition of increased financial risk, and that can in fact, while providing assurance of being a very safe investment, achieve greater levels of social and environmental impact. There are certainly lots of riskier social investments, but it is possible these days to be a responsible trustee of a university endowment or pension fund and invest prudently in ways that have much higher levels of social and environmental impact.

Indeed, this is not just McConnell saying this. Larry Fink, the CEO of Blackrock [a globally significant asset manager and investment firm] recently made a statement to the effect that companies have a duty to generate and report on their efforts to achieve greater positive social impact. Impact investing is a rapidly growing field, and we do have examples in Canada of schools that are beginning to not only invest this way, but to develop courses and programs that enable alumni, for example, to contribute to funds that invest in social enterprises, so we're excited for the sector and look forward to getting to work with leading practitioners and social investors.

Chad: Within that light, our focus is yes, schools have endowments, but for most Canadian institutions, the financial assets that they use for their operating costs are more important than their endowments. Most Canadian schools don't have endowments the way they might have in the United States. So the focus of our conversations has been working, for example, with the Canadian Association of Business Officers to look at more everyday practices than at endowments.

Stephen: A couple of the ways where I think we're seeing real progress... we mentioned the social enterprise incubators and activities going on around those. At Concordia, there's a program called the Art Hive initiative, which locates part of the university's fine arts department in a low-income community setting with students taking courses on community-engaged art and which invite community members in to explore communitydetermined priorities with the university as the host, students as the facilitators, and faculty as the overall guides and enablers.

We've been thrilled to watch art hives spread to over 100 locations around the world. And so there's clearly an appetite in community for some of the convening, hosting, learning, teaching, exploration, research capabilities of the university. I think there's a very rich area here for innovation and further work.

Chad: We see it with journalism. We see it with business; to some degree with engineering. So, thinking aloud here, I wonder if it's easier to do this when there's an opportunity to apply a skill. When there's the application, independent from the skill of research, of gathering knowledge.

David: So, I want to get back to that wider question, then, on McConnell's role. Stephen, at the very beginning you mentioned the practice of integrating the two arms of McConnell's work, grants-making activities and investment activities. In that vein, that's another one 
of these changes that people have noticed around traditional roles of philanthropy. Traditionally, philanthropy sought to correct for the imperfections of market-based systems producing inequitable outcomes. So philanthropy would try and ameliorate that in some sense, whereas today, foundations often operate to connect the social sector to the market. Is that McConnell's role then? Is McConnell's role trying to achieve social change by bringing the social sector and the community sector to the market?

Stephen: Right. I think that what you're pointing to is that there's a tectonic shift underway across the horizons or frontiers that separate the private, public, and civil society or philanthropic sectors. There's currently a federal steering committee on social innovation and social finance.

David: Are you engaged in that, by the way — in that particular federal policy initiative [on social innovation and social finance]?

Stephen: Yes, I am one of the seventeen public members of that committee. We're in the midst of that work right now with the expectation that we'll have something to share with Canadians by June 2018.

But that idea of the changing relationship among the sectors... we can look at the private sector. Increasingly, their priority has to be the renewal of social license. Not to mention talent attraction and retention. Not to mention tapping into the wellsprings of innovation that exist within civil society. So, the private sector has a renewed mandate, to find itself in the current situation. I mentioned Larry Fink's letter to corporate CEOs a couple of weeks ago_- calling on them to consciously and explicitly commit to social and environmental outcomes, to the good that they do. That is a good example of the change in the landscape.

And I think in this context, universities and colleges have a critical role to play in enabling of these cross-sectoral, cross-disciplinary conversations, and so that's a key capability, or asset - that universities are well-positioned to convene organizations across sectors. But it does depend on making a conscious commitment to engage, listen, and convene. And I think students are doing this. They seem to be agnostic these days about whether they're working for a not for profit, a for-profit, or a public sector organization. They are motivated to be engaged in making change.

I think if we look at where they're going and their needs, we're really at the service of the next generation here, and so I think together, philanthropy and the postsecondary sector, if we have a role at all, it's not to set public policy, it's to catalyze change that wants to happen anyway. We provide capital that's risk capital. We can make mistakes. We can support exploration. But we're not running the university. We're not running the government. We are a complement, an add-on, a place to do safe experimentation, rapid prototyping, and development of testable hypotheses.

In that sense, we've got, I think, a role that extends back into history, but right now 
seems important and certainly the partnerships that we're developing with multiple universities and colleges suggests that it's a needed one at this time.

David: So, Stephen, just to explore further that advocacy role. McConnell clearly states on its website that it does have an advocacy role, in a nonpartisan way, and does advocate for certain positions on behalf of your partners. And clearly you do have an influence. You are a major influencer of higher education activity in the country, so maybe if you could add a little about that advocacy role in higher education?

Stephen: I just want to sort of step back from the word advocacy.

David: Okay.

Stephen: Advocacy has some political connotations. We had a decade in Canada when foundations and civil society organizations were-how should we put this- under some pressure not to speak up on certain public issues, so a number of political audits were carried out on charities. Those were painful and prolonged, and ultimately set aside in most or almost every case. But the role of advocacy and civil society deserves to be unpacked here. First of all, I think foundations have a responsibility to speak up with and on behalf of the charities they support, because they're often more vulnerable than we are. We have assets. We're not afraid of losing our government funding and so on. So, we do have that role as an advocate for the public good.

I think we have common cause with the postsecondary system at a governance level, and at a level of the overall social project and the goods that we can bring to it. If you say, 'Are we advocating to the postsecondary sector,' I would say it's more of a case of advocating with. I mean, we are responding to the leadership in the sector that's saying, as many of these institutions are, we want to shift and expand our civic footprint. We have a community-based research agenda. We have a need to contribute to society's efforts to improve equitable access to the job market or to reducing racism, or to increasing our ability to transition to a low carbon economy.

We're at the service of that. Are we advocating that universities do something? Only in the sense that we advocate that our own sector shifts its lens and aligns its efforts to the greater purpose and current challenges that we currently face. Would we advocate against? I'm struggling with this a little bit, because I think we assume that we are engaged in a common effort to improve outcomes and to increase resilience, sustainability, social inclusion, and so on. At least, that's where we start from, and we are finding that in the postsecondary sector, we have many allies and a lot of opportunity to address this work together.

David: Thank you, Stephen and Chad! 


\section{About the Contributors}

Stephen Huddart is President and CEO of the McConnell Foundation, a national private foundation based in Montreal, with additional staff in Vancouver, Toronto, and Ottawa. The Foundation has played a leading role in developing social innovation and impact investing in Canada as a founding partner of Social Innovation Generation (SiG). McConnell's other initiatives include Innoweave, the McConnell Reconciliation Initiative, Cities for People, RECODE, and Well Ahead. Stephen serves on the Boards of Pearson College UWC. He is a former member of the Government of Canada's Social Innovation and Social Finance Strategy Co-Creation Steering Group. Stephen has worked as a social innovator and entrepreneur in the private, public, and community sectors, and holds a Masters of Management degree from McGill University. Email: shuddart@mcconnellfoundation.ca

Chad Lubelsky is a Program Director with the McConnell Foundation where he is the lead for public interest journalism and RECODE_- a pan-Canadian initiative to provide Social Innovation tools and opportunities for College and Universities to become drivers of progress and community change. Prior to joining the Foundation, Chad was the Executive Director of Santropol Roulant, developed leadership and community engagement programs for the Canada Millennium Scholarship Foundation, worked as an Assignment Editor for NBC news in San Francisco, managed global Internet Rights advocacy for the South African-based Association for Progressive Communications, and was a Founding Trustee of the Montreal Awesome Foundation. Chad holds a BA in Communications, and Masters degrees in Communications and Leadership. Email: clubelsky@mcconnellfoundation.ca

Dr. David Peacock is the Executive Director of Community Service-Learning in the Faculty of Arts at the University of Alberta, Canada. His research encompasses global service-learning, student equity policy and practices in higher education, curriculum theory, communityuniversity engagement, and 'first generation' university students' participation in experiential learning programs. David is active in developing Canadian networks for community-engaged learning and research, most recently as an Academic Co-Lead with the Community First: Impacts of Community Engagement project. Email: peacock1@ualberta.ca

Engaged Scholar Journal: Community-Engaged Research, Teaching and Learning 